Research Article

\title{
Pulse Electrodeposition of Palladium Nanoparticles onto Silicon in DMSO
}

\author{
Orest Kuntyi, ${ }^{1}$ Mariana Shepida ${ }^{D},{ }^{1}$ Oksana Dobrovetska, ${ }^{1}$ Stepan Nichkalo ${ }^{D},{ }^{1}$ \\ Sergiy Korniy, ${ }^{2}$ and Yuriy Eliyashevskyy ${ }^{3}$ \\ ${ }^{1}$ Lviv Polytechnic National University, Lviv 79013, Ukraine \\ ${ }^{2}$ Karpenko Physico-Mechanical Institute of the NAS of Ukraine, Lviv 79060, Ukraine \\ ${ }^{3}$ Ivan Franko National University of Lviv, Lviv 79005, Ukraine
}

Correspondence should be addressed to Mariana Shepida; maryana_shepida@ukr.net

Received 8 August 2019; Accepted 11 October 2019; Published 30 October 2019

Academic Editor: Sedat Yurdakal

Copyright (C) 2019 Orest Kuntyi et al. This is an open access article distributed under the Creative Commons Attribution License, which permits unrestricted use, distribution, and reproduction in any medium, provided the original work is properly cited.

\begin{abstract}
The deposition of palladium nanoparticles (PdNPs) on the surface of $\mathrm{n}$-Si (100) substrate by pulsed electrolysis in dimethyl sulfoxide (DMSO) solutions of $\mathrm{Pd}\left(\mathrm{NO}_{3}\right)_{2}$ was investigated. It has been shown that nonaqueous medium (DMSO) contributes the Pd (II) recovery at high cathode potential values avoiding side processes to occur. In combination with the pulse mode, this allows the deposition of spherical PdNPs with their uniform distribution on the silicon surface. We established that the main factors influencing the geometry of PdNPs are the value of the cathode potential, the concentration of palladium ions in solution, and the number of pulse-pause cycles. It is shown that with increasing $E_{\text {cathode }}$ value there is a tendency to increase the density of silicon surface filling with nanoparticles. As the concentration of $\mathrm{Pd}\left(\mathrm{NO}_{3}\right)_{2}$ increases from 1 to $6 \mathrm{mM}$, the density of silicon surface filling with PdNPs and their average size also increase. We found that with increasing the number of pulse-pause cycles, there is a predominant growth of nanoparticles in diameter, which causes 2D filling of the substrate surface.
\end{abstract}

\section{Introduction}

The deposition of metal nanoparticles (MNPs) on a silicon surface is one of its modifying methods to obtain (i) silicon nanowires (SiNWs) and nanomatrices [1-3], (ii) elements of highly sensitive sensors [4-6], (iii) water-splitting photoelectrodes for hydrogen generation $[7,8]$, and so on. Electrolysis is an effective way to form the MNPs/Si surface systems $[9,10]$ due to the relative simplicity of hardware and technology. The most studied is the electrodeposition of noble metals that is caused due to their high stability and high values of the standard electrode potential $\left(E_{\mathrm{Au}^{3+} / \mathrm{Au}}^{0}=1.49 \mathrm{~V}\right.$ and $\left.E_{\mathrm{Pd}^{2+} / \mathrm{Pd}^{2}}^{0}=0.987 \mathrm{~V}\right)$. The latter is especially important for providing a high value of $\Delta E^{0}\left(\Delta E^{0}=E_{\mathrm{M}^{n+} / \mathrm{M}}^{0}-E_{\mathrm{Si}^{++} / \mathrm{Si}}^{0}\right)$, which is identical to the high etching rate of silicon during the formation of the nanoporous surface [1-3].

By varying the electrolyte composition, the values of the cathodic potential or current density, and the methods of current supply (stationary, cyclic, and pulsed), it is possible to obtain MNPs of various shapes and sizes on the silicon surface. Most of the studies on electrochemical production of MNPs/Si surface systems have been performed in aqueous solutions (see Table 1) [9-28]. However, the water factor as a medium does not always provide the ability to control the geometry of MNPs at the main stages of their formation: cathodic reduction (1), nucleation, i.e., formation of metal nanoclusters (MNCs) (2), and nanoparticles (3). After all, at high values of cathodic potential $\left(E_{\text {cathode }}\right)$ and low concentrations of reducible metal ions which is a prerequisite for the deposition of MNPs, parallel processes take place, e.g., the cathode reaction (4) and the interaction of silicon with water (5).

$$
\begin{aligned}
\mathrm{M}^{\mathrm{n}+}+\mathrm{ne} & \longrightarrow \mathrm{M}^{0} \\
\mathrm{mM}^{0} & \longrightarrow \text { MNCs }
\end{aligned}
$$




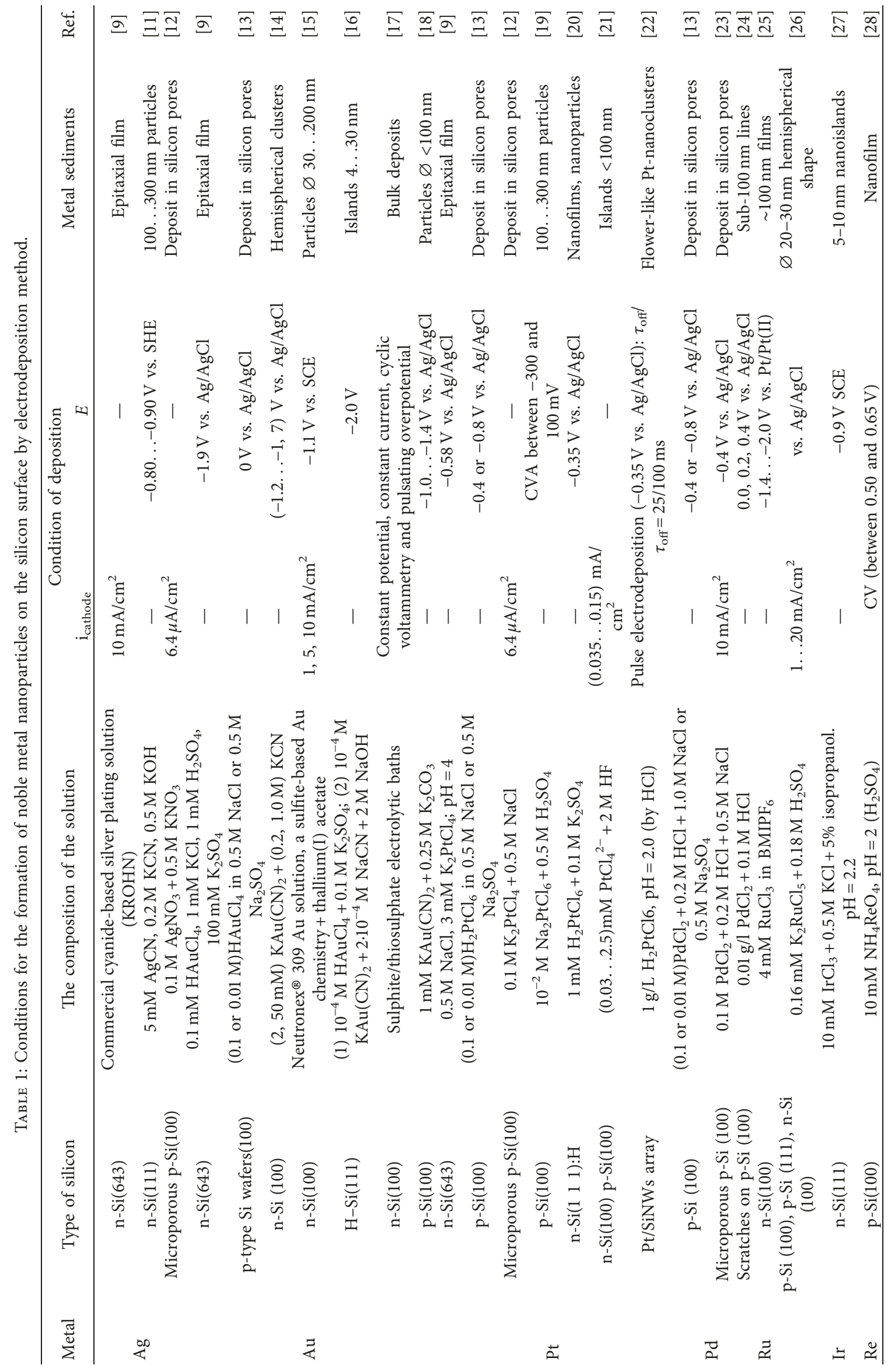




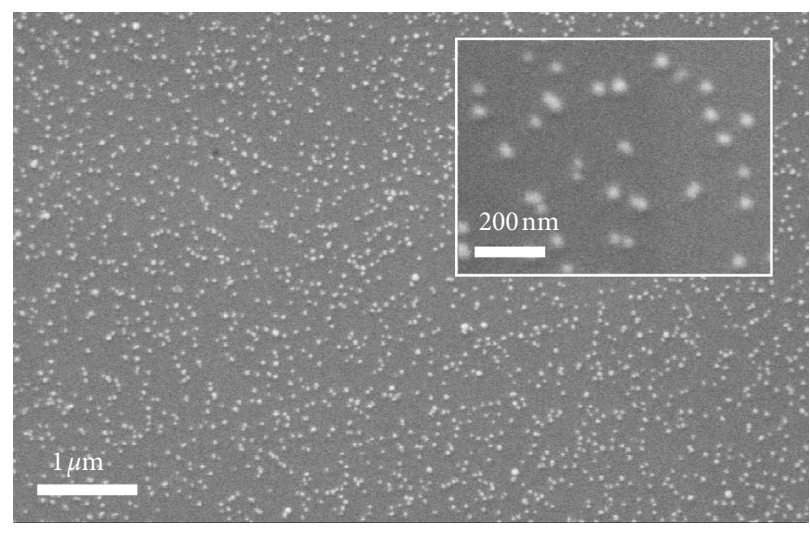

(a)

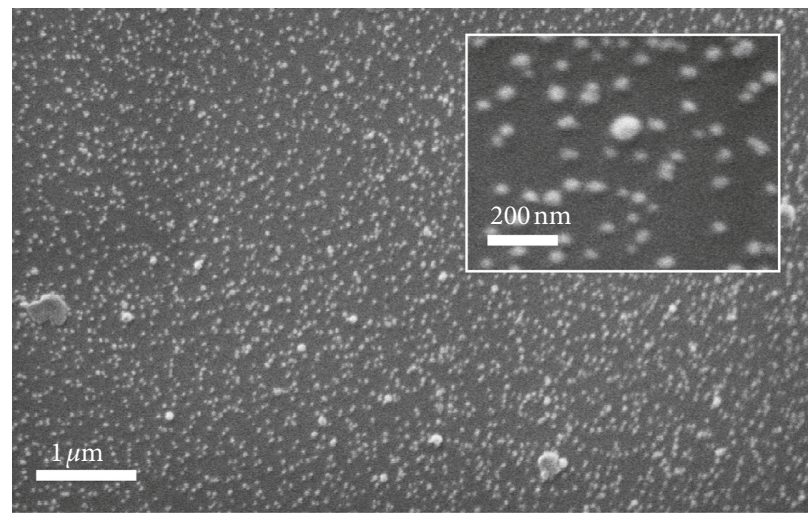

(c)

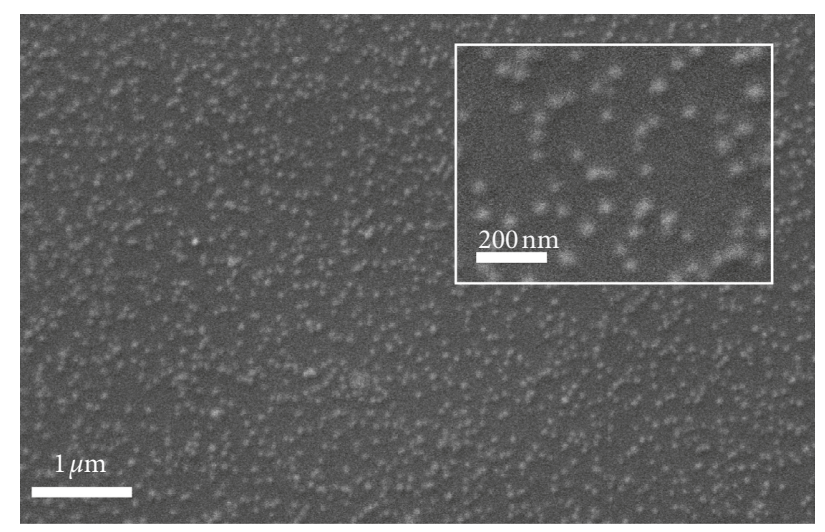

(b)

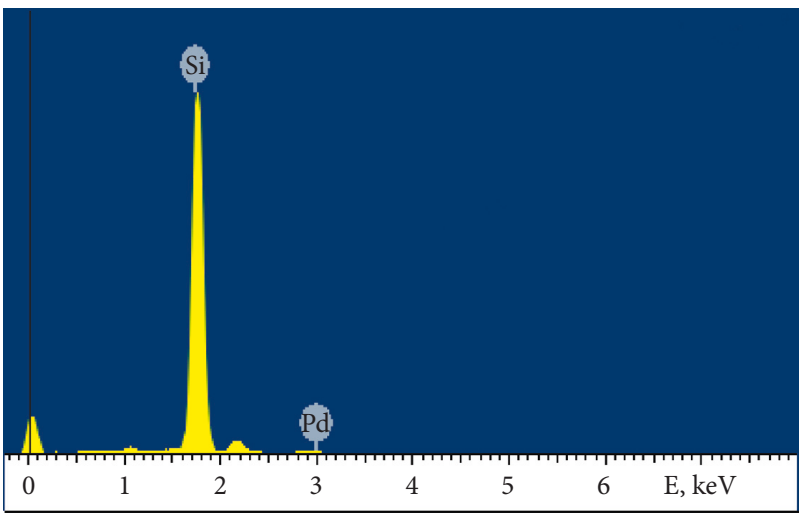

(d)

Figure 1: SEM images of PdNPs on the silicon surface obtained by electrolysis in a solution of $4 \mathrm{mM} \mathrm{Pd}\left(\mathrm{NO}_{3}\right)_{2}+50 \mathrm{mM} \mathrm{Bu}_{4} \mathrm{NClO}_{4}$ mixed with DMSO for 400 cycles at $E_{\text {cathode }}(\mathrm{V}):-1.8$ (a), -2.0 (b), -2.2 (c), and EDX-spectrum (d).

$$
\begin{aligned}
\mathrm{MNCs}+\mathrm{pM}^{0} \longrightarrow \mathrm{MNPs} \\
2 \mathrm{H}_{2} \mathrm{O}+2 \mathrm{e} \longrightarrow \mathrm{H}_{2}+2 \mathrm{OH}^{-} \\
\mathrm{Si}+2 \mathrm{H}_{2} \mathrm{O} \longrightarrow \mathrm{SiO}_{2}+4 \mathrm{H}^{+}
\end{aligned}
$$

Reaction (4) due to gas evolution causes the local turbulence of electrolyte and, accordingly, the instability of the mass transfer of metal ions into the pre-electrode layer. Reaction (5) results in the passivation of the silicon surface. To prevent such undesirable processes, a nonaqueous medium may be used as it was shown previously in [29-32], where the deposition of metals on silicon was performed in organic solvents. However, these papers report about the deposition of noble metals via the galvanic replacement method. Electrodeposition on the silicon surface in organic solvents has not been practically studied wide. Moreover, the formation of a nanostructured $\mathrm{Ru} / \mathrm{Si}$ surface at high cathodic potentials from an ionic liquid [25] indicates the prospect of such a direction of silicon surface modification. The purpose of this work is to establish the conditions of deposition of PdNPs on a silicon surface in dimethyl sulfoxide (DMSO) solutions under a pulsed electrolysis regime. Application of pulse electrodeposition and the use of organic aprotic solvents allow ensuring the concentration stability of reducible metal ions in the preelectrode layer at high $E_{\text {cathode }}$ values. As shown in $[33,34]$, this provides conditions for the controlled deposition of MNPs of a certain geometry.

\section{Experimental}

Crysteco $n$-Si (100) wafers with resistivity $4.5 \Omega \cdot \mathrm{cm}$ were used for the experiments. Wafers were cut into equal samples of $1 \times 1 \mathrm{~cm}^{2}$. Palladium deposition on a silicon surface was carried out by electrolysis from solutions of 1,2 , 4 , and $6 \mathrm{mM} \mathrm{Pd}\left(\mathrm{NO}_{3}\right)_{2}+50 \mathrm{mM} \mathrm{Bu}_{4} \mathrm{NClO}_{4}$ in DMSO solvent. The working electrode was the n-type Si (100) cremation plate, the anomalous platinum plate $\left(S=2.7 \mathrm{~cm}^{2}\right)$. A silver chloride electrode manufactured as $\mathrm{Ag} / \mathrm{AgCl}$ in saturated $\mathrm{KCl}$ solution was used as the reference electrode. Before electrolysis, the silicon samples were etched for $10 \mathrm{~s}$ in HF solution to remove the oxide film from the substrate surface. After that, the surface of the working electrode was washed with DMSO solvent. Subsequently, the three electrodes were connected to an IPC-Pro 200 potentiostat and immersed into a glass cell filled with $\sim 50 \mathrm{~cm}^{3}$ of the electrolyte at $25^{\circ} \mathrm{C}$. Palladium was precipitated under pulsed electrolysis mode: pulse time $\left(\tau_{\text {on }}\right) 6 \mathrm{~ms}$ and pauses $\left(\tau_{\text {off }}\right)$ $300 \mathrm{~ms}$ at $E=-1.8,-2.0$, and $-2.2 \mathrm{~V}$ for $25,50,100$, and 400 


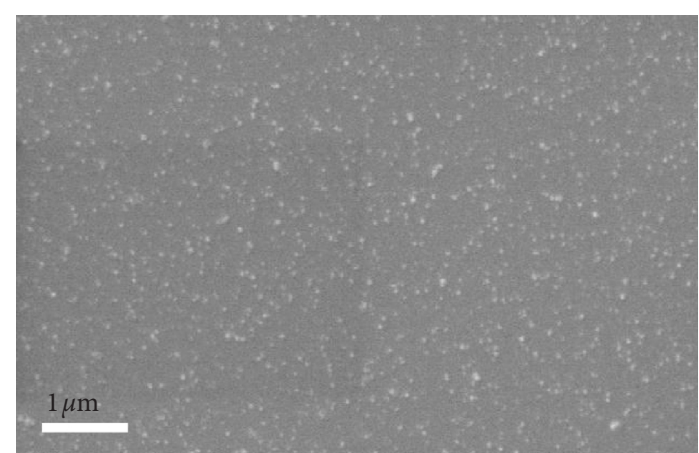

(a)

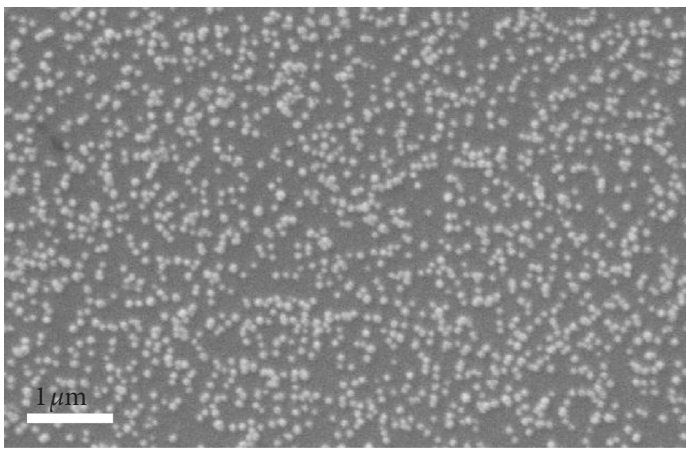

(c)

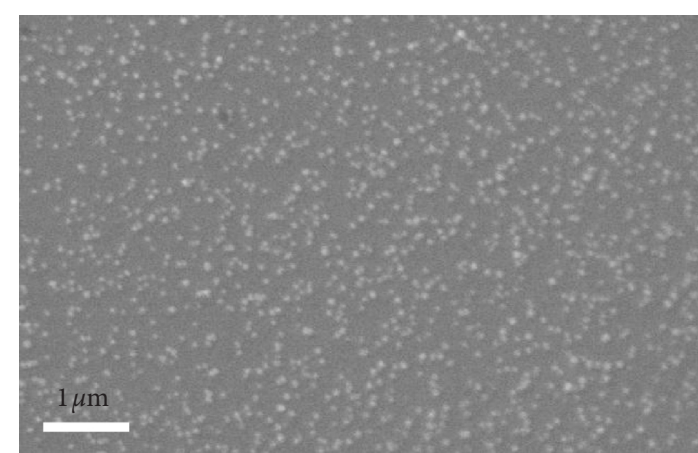

(b)

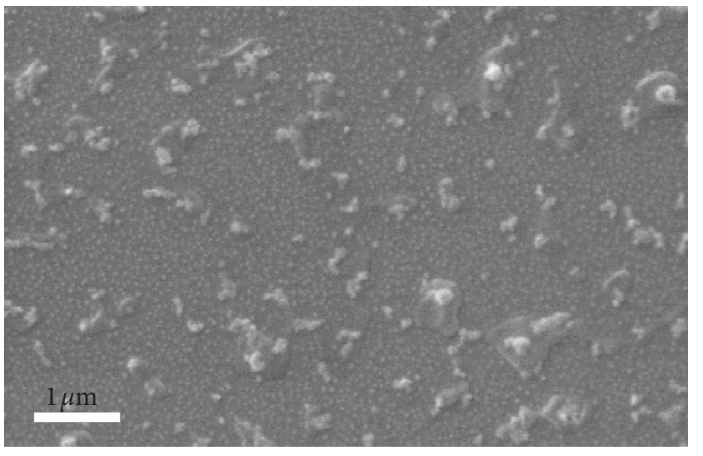

(d)

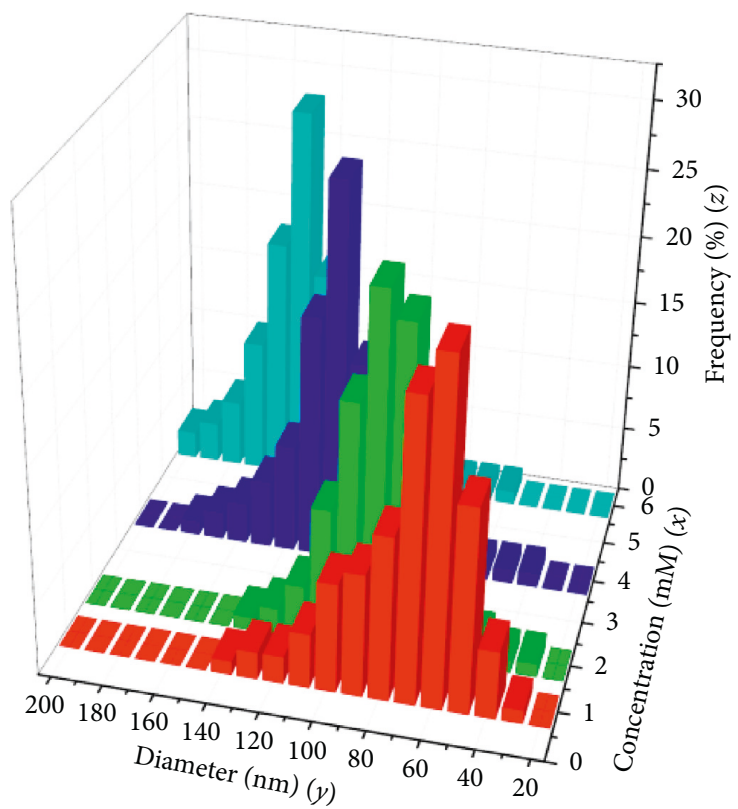

(e)

FIgURE 2: SEM images of PdNPs on the silicon surface obtained by electrolysis in a solution containing $1 \mathrm{mM}$ (a), $2 \mathrm{mM}$ (b), $4 \mathrm{mM}$ (c), and $6 \mathrm{mM}(\mathrm{d})$ of $\mathrm{Pd}\left(\mathrm{NO}_{3}\right)_{2}, 50 \mathrm{mM} \mathrm{Bu}_{4} \mathrm{NClO}_{4}$, and DMSO for 400 cycles at $E_{\text {cathode }}=-2.0 \mathrm{~V}$ and the size distribution histograms of PdNPs (e).

cycles. After the process is completed, the palladium-precipitated samples were washed with ethanol and air-dried.

The morphology and composition of sediment on the silicon surface were studied using a ZEISS EVO 40XVP scanning electron microscope (SEM) and a Solver P47-PRO atomic force microscope (AFM). The images of the modified surface were obtained by recording secondary electrons by scanning an electron beam of $15 \mathrm{kV}$ energy. The chemical composition of the resulting precipitates was characterized using energy-dispersive X-ray spectroscopy (EDX).

The statistical histograms were obtained using Origin software pack with its standard deviation values of 


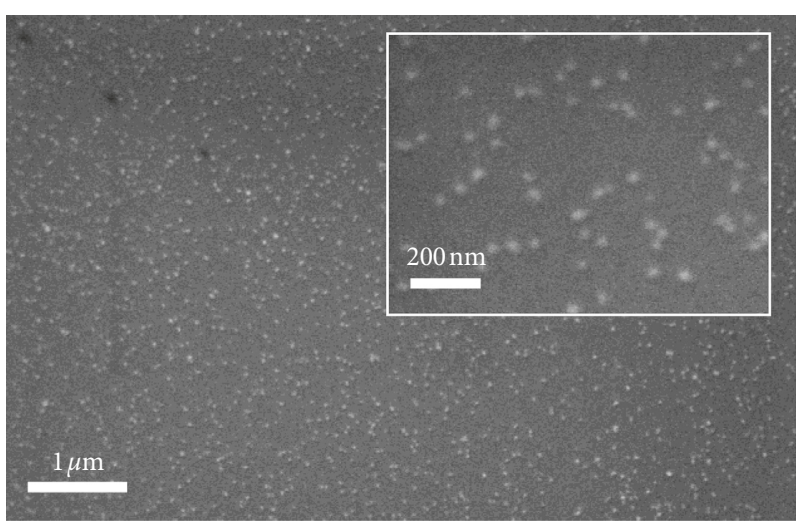

(a)

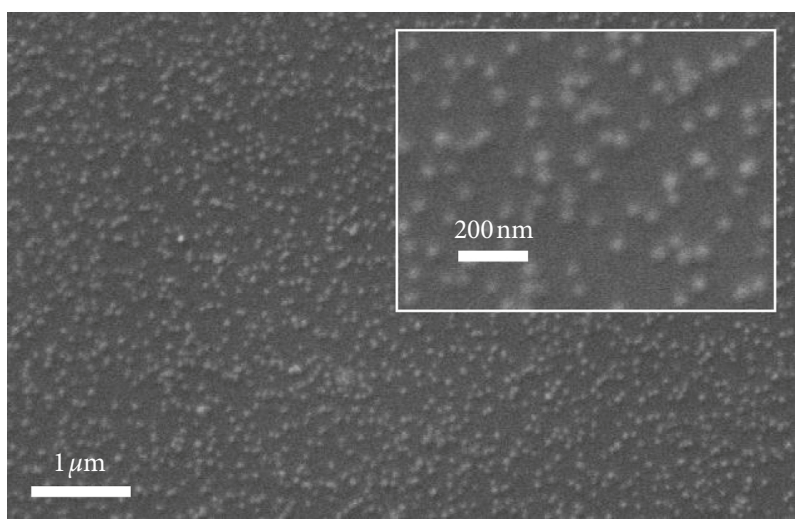

(c)

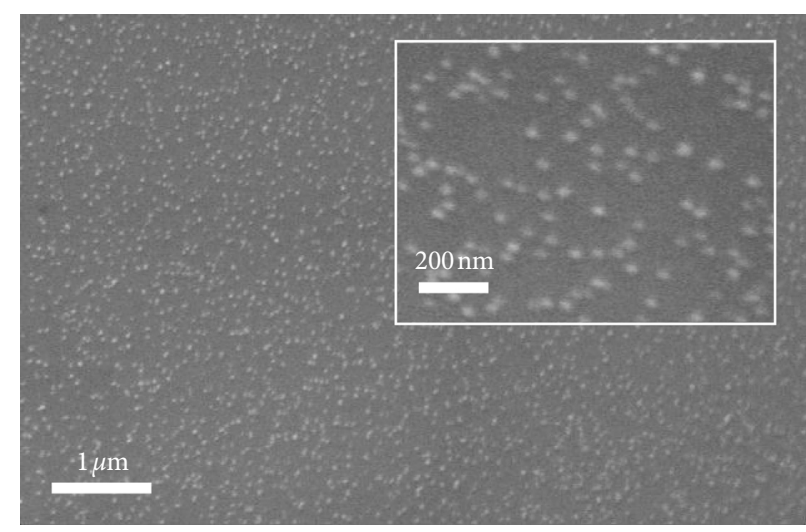

(b)

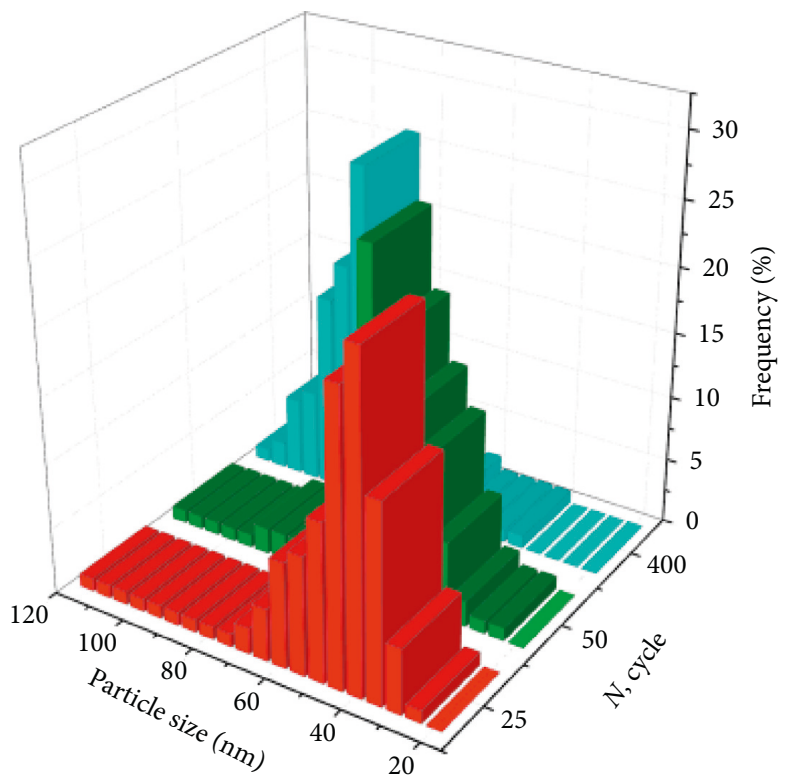

(d)

Figure 3: SEM images of PdNPs on the silicon surface obtained by electrolysis in a solution containing $4 \mathrm{mM}$ of $\mathrm{Pd}\left(\mathrm{NO}_{3}\right)_{2}, 50 \mathrm{mM}$ $\mathrm{Bu}_{4} \mathrm{NClO}_{4}$, and DMSO at $E_{\text {cathode }}=-2.0 \mathrm{~V}$ for 25 (a), 50 (b), and 400 (c) cycles and the size distribution histograms of PdNPs (d).

nanoparticle size. Additionally, NPs size and density were determined by using the public domain Java image processing program ImageJ2 [35].

\section{Results and Discussion}

Electrochemical deposition of metals on the silicon surface differs significantly from deposition on a metal substrate. This is due to the electrical conductivity of $n$-Si or $p$-Si substrate which is much lower than metallic one, which causes poor cathodic metal reduction on a semiconductor surface. As a result, this leads to the priority 3D island growth, which is caused by the prevailing reaction rate (1) at the metal surface, resulting in the formation of nucleation centers [8]. Therefore, in order to ensure a constant nucleation on the doped Si surface during the electrodeposition, it must be periodically excited. This function is performed by the pulse mode of electrolysis at high cathode potentials $\left(E_{\text {cathode }}\right)$. To determine the dependence of the size of electrodeposited Pd particles and their distribution on the silicon surface from the electrolysis conditions, we studied the impact of the following main factors: (i) the value of the cathode potential, (ii) the concentration of $\mathrm{Pd}$ ions in solution, and (iii) the number of pulse-pause cycles.

In a wide range of the $E_{\text {cathode }}$ values (Figure 1 ), the concentration of palladium ions (Figure 2) and regardless of the number of pulse-pause cycles (Figure 3), the formation of spherical metal particles is observed. This is explained by the influence of DMSO donor molecules (L), notably the formation of surface complexes due to the donor-acceptor interaction. These complexes are formed primarily on the ledges, which block them and prevent dendritic formation.

3.1. Impact of the Cathode Potential. With the increase of $E_{\text {cathode }}$, there is an upward trend in the density of the silicon surface filling with $\mathrm{Pd}$ particles and their size increases (Figure 1). Therefore, we can assume that the pulse regime of electrodeposition leads simultaneously to the nucleation and 

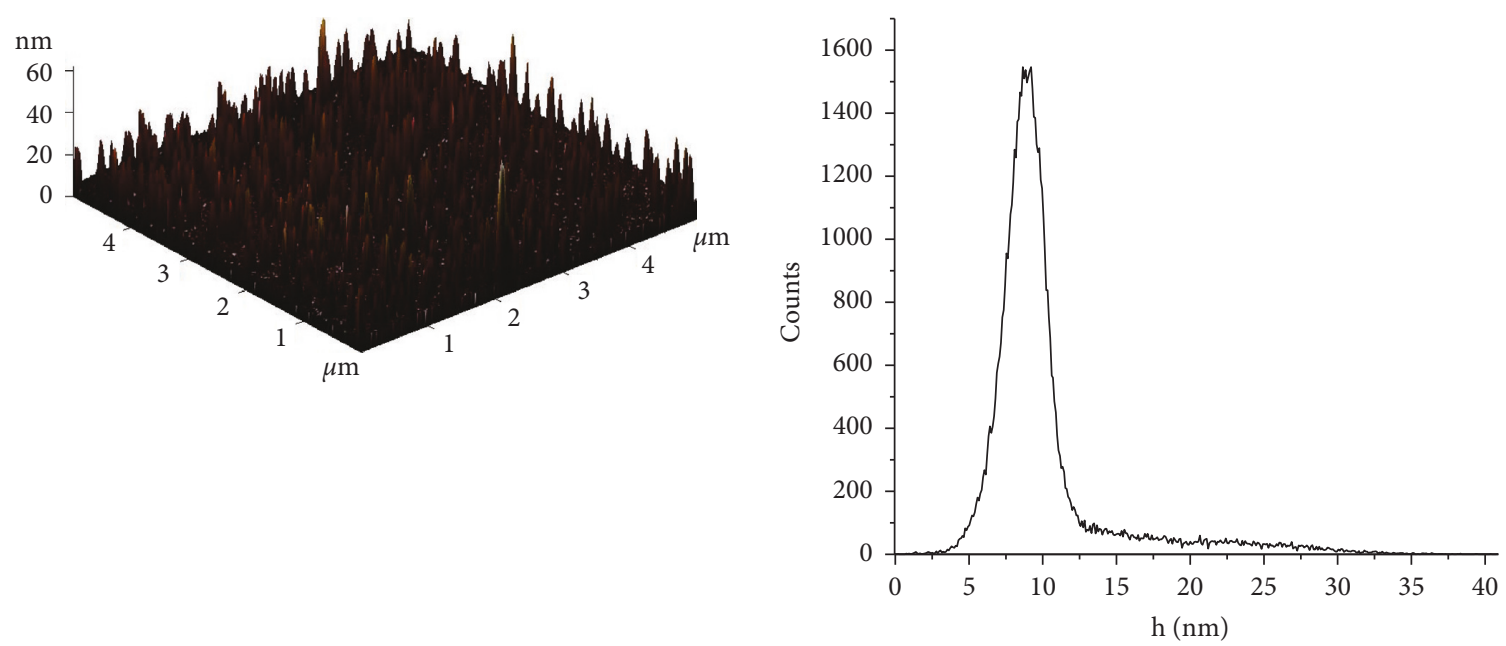

(a)
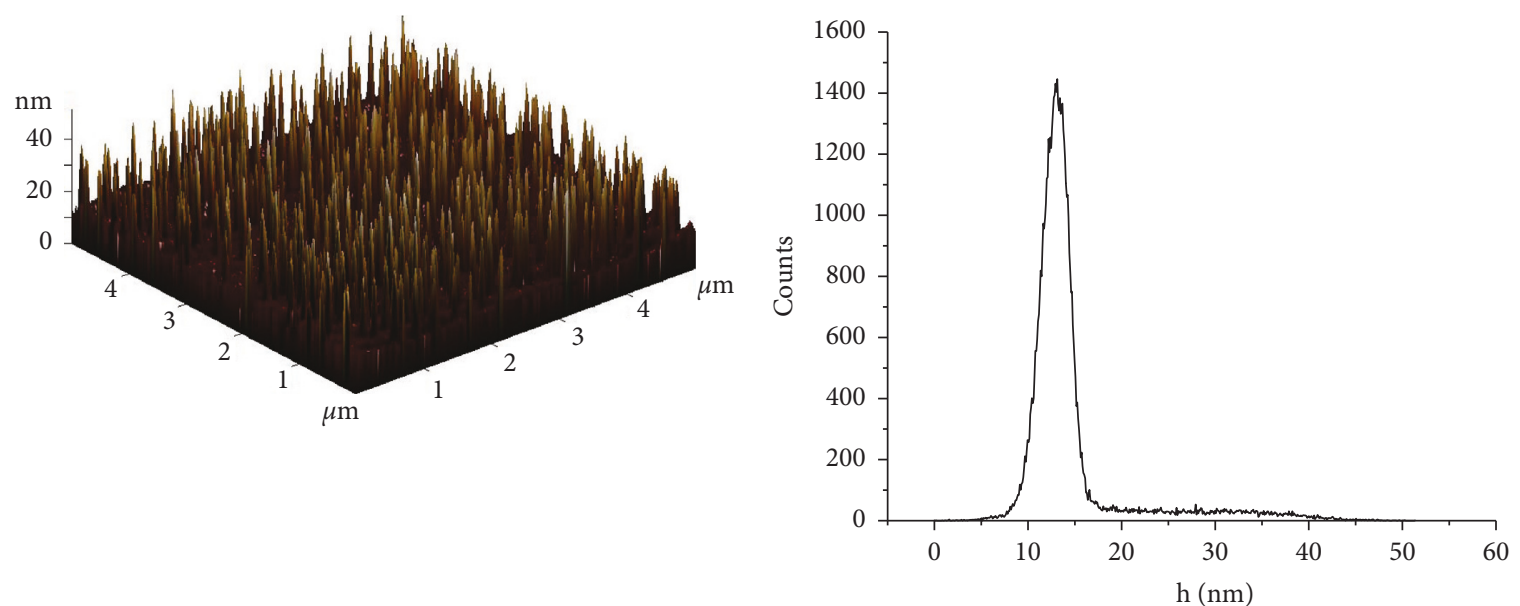

(c)
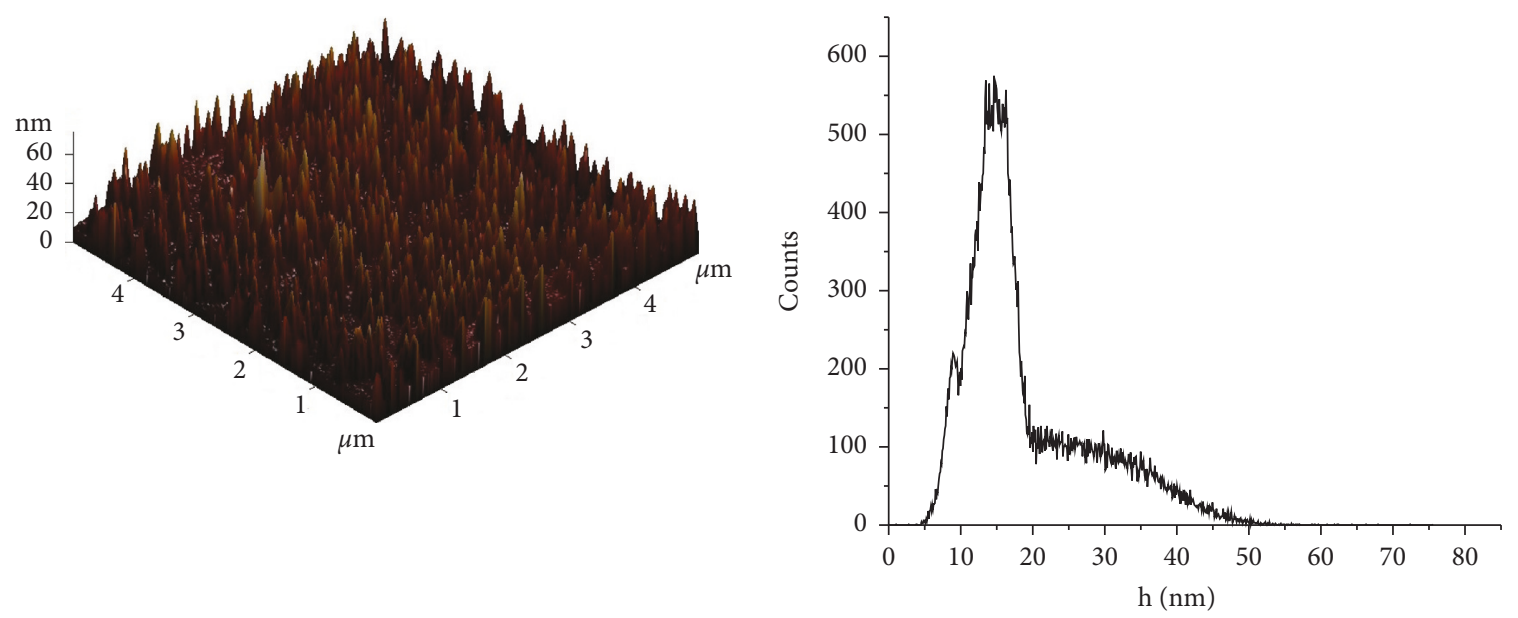

(e)

(f)

FIGURE 4: AFM images of PdNPs obtained by electrolysis in a solution containing $4 \mathrm{mM}$ of $\mathrm{Pd}\left(\mathrm{NO}_{3}\right)_{2}, 50 \mathrm{mM} \mathrm{Bu}_{4} \mathrm{NClO}_{4}$, and $\mathrm{DMSO}$ at $E_{\text {cathode }}=-2.0 \mathrm{~V}$ after 25 (a), 50 (c), and 400 (e) cycles and the height distribution histograms of PdNPs (b, d, and f).

growth of PdNPs on the semiconductor substrate. It is expected that higher $E_{\text {cathode }}$ values, as an energy factor, contribute to this. The $-1.8 \ldots-2.2 \mathrm{~V}$ range determines the maximum values of the cathode currents. The latter provides a high deposition rate of palladium nanoparticles (PdNPs), their small size, and uniform distribution across the substrate surface. Thus, for $E_{\text {cathode }}=-1.8 \mathrm{~V}$ (Figure $1(\mathrm{a})$ ), $-2.0 \mathrm{~V}$ (Figure 1(b)), and $-2.2 \mathrm{~V}$ (Figure 1(c)), the number of 
particles, respectively, is 8,14 , and 18 per $1 \times 1 \mu \mathrm{m}^{2}$. So, when $E_{\text {cathode }}$ increases, the tendency for agglomeration of PdNPs is observed (Figure 1(c)).

3.2. Impact of the Concentration of Pd Ions. Pulse-mode electrolysis at $\tau_{\text {on }}=6 \mathrm{~ms}$ and $\tau_{\text {off }}=300 \mathrm{~ms}$ provides diffusion of solvated ions of $\left[\mathrm{Pd}(\mathrm{DMSO})_{n}\right]^{2+}$ to the cathode surface during the pause. Therefore, for each pulse-pause cycle, the reduction of $\mathrm{Pd}$ during the pulse occurs at a stable concentration of $\mathrm{Pd}(\mathrm{II})$. This contributes to the relatively uniform distribution of PdNPs over the substrate surface (Figures 2(a)-2(d)) and their small size variation (Figure 2(e)). With increasing concentration of ions of $\left[\mathrm{Pd}(\mathrm{DMSO})_{\mathrm{n}}\right]^{2+}$ which is caused by high mass transfer, the average particle size also increases significantly. Thus, discrete PdNPs with an average size of 75, 95, and $115 \pm 10 \mathrm{~nm}$ are precipitated from solutions containing 1, 2, and $4 \mathrm{mM}$ of $\mathrm{Pd}\left(\mathrm{NO}_{3}\right)_{2}$, respectively. In a solution of $6 \mathrm{mM} \mathrm{Pd}\left(\mathrm{NO}_{3}\right)_{2}$, agglomeration of PdNPs is observed with the formation of nanofilm fragments. Consequently, the size of the precipitated PdNPs is very sensitive to the concentration of $\mathrm{Pd}(\mathrm{II})$, which can be considered as one of the main factors influencing the morphology of the metal precipitate and the geometry of its structural particles. As we can see in Figure 2, the amount of $\mathrm{Pd}\left(\mathrm{NO}_{3}\right)_{2}$ in the solution did not influence the increase in the concentration of Pd precipitates.

3.3. Impact of the Number of Pulse-Pause Cycles. According to the SEM images, an increase in the pulse-pause cycles tends to fill the silicon surface with PdNPs. The PdNPs with an average diameter of 55,65 , and $75 \pm 10 \mathrm{~nm}$ are precipitated from 25, 50, and 400 cycles, respectively (Figure 3). Therefore, during deposition under pulsed electrolysis mode, the nucleation and growth of PdNPs occur simultaneously.

The AFM results (Figure 4) are shown to demonstrate the growth of nanoparticles in height with increasing electrodeposition duration (number of cycles) at $\mathrm{E}=-2.0 \mathrm{~V}$. As shown in Figure 4, when the number of cycles increases, the height of PdNPs changes slightly. Thus, after 25 cycles, the average height of PdNPs is about $9 \mathrm{~nm}$ (Figure 4(b)) and after 50 and 400 cycles, the average height of PdNPs is about $14 \mathrm{~nm}$ (Figure 4(c)) and $17 \mathrm{~nm}$ (Figure 4(f)), respectively. The same trend was observed for other values of $E_{\text {cathode. }}$

The effect of suppression of the growth of NPs in height can be attributed to electrochemical Ostwald ripening [36]. In fact, the adhesion of MNPs to the surface of semiconductors is lower than that of metals [37]. So, this facilitates the migration of small nanoparticles across the substrate surface and their absorption by larger $2 \mathrm{D}$ nanoparticles.

\section{Conclusions}

Palladium nanoparticles with an average size of 40-160 nm are deposited on the silicon surface from solutions containing 1-6 mM Pd( $\left.\mathrm{NO}_{3}\right)_{2}$ and DMSO by the pulsed electrolysis method at $E_{\text {cathode }}=-1.8 \ldots-2.2 \mathrm{~V}$. The organic aprotic solvent medium prevents the side cathodic processes to occur during electrochemical reduction of $\mathrm{Pd}(\mathrm{II})$ at high cathode potentials. The latter contributes to the energy excitation of the doped semiconductor surface, which causes the formation of discrete PdNPs uniformly distributed on the substrate surface. The electron donor nature of DMSO molecules and the pulsed electrolysis mode induce the deposition of spherical nanoparticles and the $2 \mathrm{D}$ filling of the silicon surface during electrolysis. The main factors influencing the size of PdNPs are the value of the cathode potential, the concentration of palladium ions in solution, and the number of pulse-pause cycles. As these values increase, the nanoparticle size and the density of the substrate surface filling increase.

\section{Data Availability}

The data used to support the findings of this study are included within the article.

\section{Conflicts of Interest}

The authors declare that there are no conflicts of interest regarding the publication of this paper.

\section{Acknowledgments}

This work was financially supported by the Ministry of Education and Science of Ukraine under the project "Controlled electrochemical synthesis of metal nanoparticles and nanostructured materials" (State registration number: 0118U000268).

\section{References}

[1] H. Han, Z. Huang, and W. Lee, "Metal-assisted chemical etching of silicon and nanotechnology applications," Nano Today, vol. 9, no. 3, pp. 271-304, 2014.

[2] O. I. Kuntyi, G. I. Zozulya, M. V. Shepida, and S. I. Nichkalo, "Deposition of nanostructured metals on the surface of silicon by galvanic replacement: a mini-review," Voprosy Khimii $i$ Khimicheskoi Tekhnologii, vol. 2019, no. 3, pp. 74-82, 2019.

[3] K. Rajkumar, R. Pandian, A. Sankarakumar, and R. T. Rajendra Kumar, "Engineering silicon to porous silicon and silicon nanowires by metal-assisted chemical etching: role of $\mathrm{Ag}$ size and electron-scavenging rate on morphology control and mechanism," ACS Omega, vol. 2, no. 8, pp. 4540-4547, 2017.

[4] V. Myndrul, R. Viter, M. Savchuk et al., "Porous silicon based photoluminescence immunosensor for rapid and highlysensitive detection of ochratoxin A," Biosensors and Bioelectronics, vol. 102, pp. 661-667, 2018.

[5] M. D. Sonawane and S. B. Nimse, "Surface modification chemistries of materials used in diagnostic platforms with biomolecules," Journal of Chemistry, vol. 2016, Article ID 9241378, 19 pages, 2016.

[6] G. Behzadi Pour, L. Fekri Aval, M. Nasiri Sarvi, S. Fekri Aval, and H. Nazarpour Fard, "Hydrogen sensors: palladium-based electrode," Journal of Materials Science: Materials in Electronics, vol. 30, no. 9, pp. 8145-8153, 2019.

[7] B. Fabre, G. Li, F. Gouttefangeas, L. Joanny, and G. Loget, "Tuning the photoelectrocatalytic hydrogen evolution of 
Pt-decorated silicon photocathodes by the temperature and time of electroless Pt deposition," Langmuir, vol. 32, no. 45, pp. 11728-11735, 2016.

[8] G. Behzadi Pour and L. Fekri Aval, "Highly sensitive work function hydrogen gas sensor based on $\mathrm{PdNPs} / \mathrm{SiO}_{2} / \mathrm{Si}$ structure at room temperature," Results in Physics, vol. 7, pp. 1993-1999, 2017.

[9] M. V. Kelso, J. Z. Tubbesing, Q. Chen, and J. A. Switzer, "Epitaxial electrodeposition of chiral metal surfaces on silicon(643)," Journal of The American Chemical Society, vol. 140, no. 46, pp. 15812-15819, 2018.

[10] Y. Ogata, K. Kobayashi, and M. Motoyama, "Electrochemical metal deposition on silicon," Current Opinion in Solid State and Materials Science, vol. 10, no. 3-4, pp. 163-172, 2006.

[11] K. Márquez, G. Staikov, and J. W. Schultze, "Silver deposition on silicon and glassy carbon. A comparative study in cyanide medium," Electrochimica Acta, vol. 48, no. 7, pp. 875-882, 2003.

[12] R. Koda, K. Fukami, T. Sakka, and Y. H. Ogata, "Electrodeposition of platinum and silver into chemically modified microporous silicon electrodes," Nanoscale Research Letters, vol. 7, no. 1, p. 330, 2012.

[13] K. Fukami, K. Kobayashi, T. Matsumoto, Y. L. Kawamura, T. Sakka, and Y. H. Ogata, "Electrodeposition of noble metals into ordered macropores in p-type silicon," Journal of the Electrochemical Society, vol. 155, no. 6, pp. D443-D448, 2008.

[14] G. Oskam and P. C. Searson, "Electrochemistry of gold deposition on $\mathrm{n}-\mathrm{Si}(100)$," Journal of the Electrochemical Society, vol. 147, no. 6, pp. 2199-2205, 2000.

[15] Q. Huang, H. Deligianni, and L. T. Romankiw, "Electrodeposition of gold on silicon nucleation and growth phenomena," Journal of the Electrochemical Society, vol. 153, no. 5, pp. C332-C336, 2006.

[16] S. Warren, P. Prod'homme, F. Maroun et al., "Electrochemical Au deposition on stepped $\mathrm{Si}(111)-\mathrm{H}$ surfaces: $3 \mathrm{D}$ versus $2 \mathrm{D}$ growth studied by AFM and X-ray diffraction," Surface Science, vol. 603, no. 9, pp. 1212-1220, 2009.

[17] M. Gamero and C. Alonso, "Deposition of nanostructurated gold on n-doped silicon substrate by different electrochemical methods," Journal of Applied Electrochemistry, vol. 40, no. 1, pp. 175-190, 2010.

[18] Y. B. Vogel, N. Darwish, M. B. Kashi, J. J. Gooding, and S. Ciampi, "Hydrogen evolution during the electrodeposition of gold nanoparticles at $\mathrm{Si}(100)$ photoelectrodes impairs the analysis of current-time transients," Electrochimica Acta, vol. 247, pp. 200-206, 2017.

[19] P. Garrido, E. Gómez, and E. Vallés, "Simultaneous electrodeposition and detection of platinum on silicon surfaces," Journal of Electroanalytical Chemistry, vol. 441, no. 1-2, pp. 147-151, 1998.

[20] A. G. Muñoz and H. J. Lewerenz, "Model experiments on electrochemical formation of nano-dimensioned noble metaloxide-semiconductor junctions at $\mathrm{Si}(111)$ surfaces," Electrochimica Acta, vol. 55, no. 26, pp. 7772-7779, 2010.

[21] P. Gorostiza, P. Allongue, R. Díaz, J. R. Morante, and F. Sanz, "Electrochemical characterization of the open-circuit deposition of platinum on silicon from fluoride solutions," The Journal of Physical Chemistry B, vol. 107, no. 26, pp. 64546461, 2003.

[22] L. Qiao, M. Zhou, Y. Li et al., "Enhancing electrochemical hydrogen generation by platinum-modification of p-type silicon wires array under visible light," Journal of the Electrochemical Society, vol. 161, no. 9, pp. H458-H463, 2014.

[23] T. Matsumoto, K. Kobayashi, K. Fukami, T. Sakka, and Y. H. Ogata, "Electrodeposition behavior of noble metals in ordered macroporous silicon," Physica Status Solidi C, vol. 6, no. 7, pp. 1561-1565, 2009.

[24] L. Santinacci, T. Djenizian, H. Hildebrand et al., "Selective palladium electrochemical deposition onto AFM-scratched silicon surfaces," Electrochimica Acta, vol. 48, no. 20-22, pp. 3123-3130, 2003.

[25] O. Raz, G. Cohn, W. Freyland, O. Mann, and Y. Ein-Eli, "Ruthenium electrodeposition on silicon from a room-temperature ionic liquid," Electrochimica Acta, vol. 54, no. 25, pp. 6042-6045, 2009.

[26] H. Ein-Eli and W. Monnens, "Immersion and electrochemical deposition of $\mathrm{Ru}$ on Si," Electrochimica Acta, vol. 274, pp. 306-315, 2018.

[27] A. G. Muñoz and H. J. Lewerenz, "Electroplating of Iridium onto single-crystal silicon: chemical and electronic properties of $\mathrm{n}-\mathrm{Si}(111) /$ Ir nanojunctions," Journal of the Electrochemical Society, vol. 156, no. 5, pp. D184-D187, 2009.

[28] E. C. Muñoz, R. S. Schrebler, M. A. Orellana, and R. Córdova, "Rhenium electrodeposition process onto $\mathrm{p}-\mathrm{Si}(100)$ and electrochemical behaviour of the hydrogen evolution reaction onto p-Si/Re/0.1M H2SO4 interface," Journal of Electroanalytical Chemistry, vol. 611, no. 1-2, pp. 35-42, 2007.

[29] O. Kuntyi, M. Shepida, L. Sus et al., "Modification of silicon surface with silver, gold and palladium nanostructures via galvanic substitution in DMSO and DMF solutions," Chemistry \& Chemical Technology, vol. 12, no. 3, pp. 305-309, 2018.

[30] M. Shepida, O. Kuntyi, G. Zozulya, and E. Kaniukov, "Deposition of palladium nanoparticles on the silicon surface via galvanic replacement in DMSO," Applied Nanoscience, pp. 1-6, 2019.

[31] M. Shepida, O. Kuntyi, S. Nichkalo, G. Zozulya, and S. Korniy, "Deposition of gold nanoparticles via galvanic replacement in DMSO and their influence on formation of silicon nanostructures," Advances in Materials Science and Engineering, vol. 2019, Article ID 2629464, pp. 1-7, 2019.

[32] F. A. Harraz, T. Tsuboi, J. Sasano, T. Sakka, and Y. H. Ogata, "Metal deposition onto a porous silicon layer by immersion plating from aqueous and nonaqueous solutions," Journal of the Electrochemical Society, vol. 149, no. 9, pp. C456-C463, 2002.

[33] L. Sus, Y. Okhremchuk, I. Saldan, O. Kuntyi, O. Reshetnyak, and S. Korniy, "Controlled gold deposition by pulse electrolysis," Materials Letters, vol. 139, pp. 296-299, 2015.

[34] I. Saldan, A. Girella, C. Milanese et al., "Size and distribution of palladium nanoparticles electrodeposited on graphite," Functional Materials, vol. 25, no. 1, pp. 082-087, 2018.

[35] C. T. Rueden, J. Schindelin, M. C. Hiner et al., "ImageJ2: ImageJ for the next generation of scientific image data," $B M C$ Bioinformatics, vol. 18, no. 1, 2017.

[36] T. Ghosh, P. Karmakar, and B. Satpati, "Electrochemical Ostwald ripening and surface diffusion in the galvanic displacement reaction: control over particle growth," RSC Advances, vol. 5, no. 114, pp. 94380-94387, 2015.

[37] T. Ghosh, P. Das, T. K. Chini, T. Ghosh, and B. Satpati, "Tilt boundary induced heteroepitaxy in chemically grown dendritic silver nanostructures on germanium and their optical properties," Physical Chemistry Chemical Physics, vol. 16, no. 31, pp. 16730-16739, 2014. 

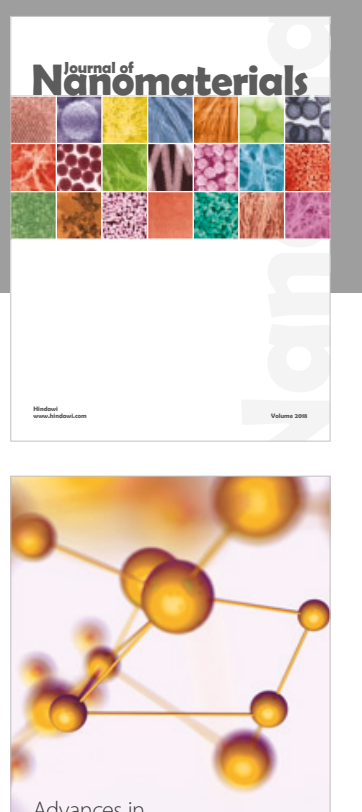

Physical Chemistry
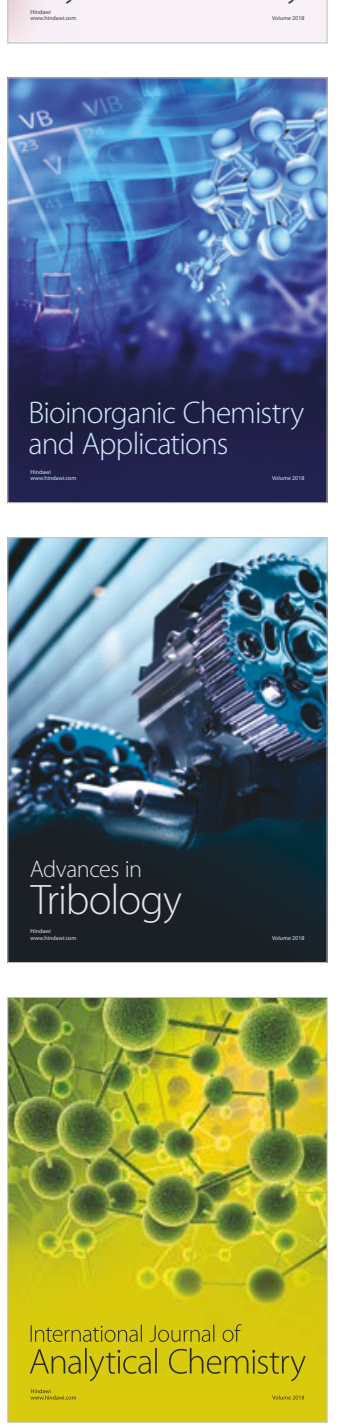

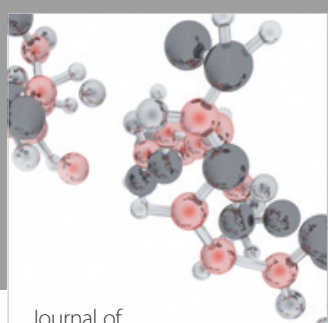

Analytical Methods

in Chemistry

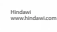

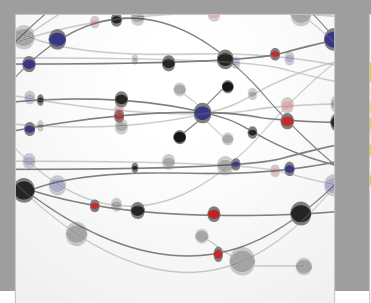

The Scientific World Journal

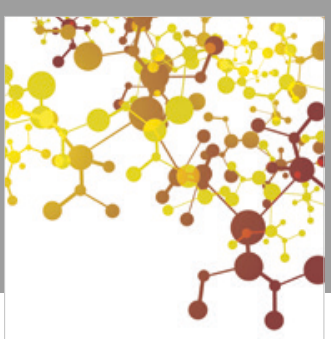

Journal of

Applied Chemistry
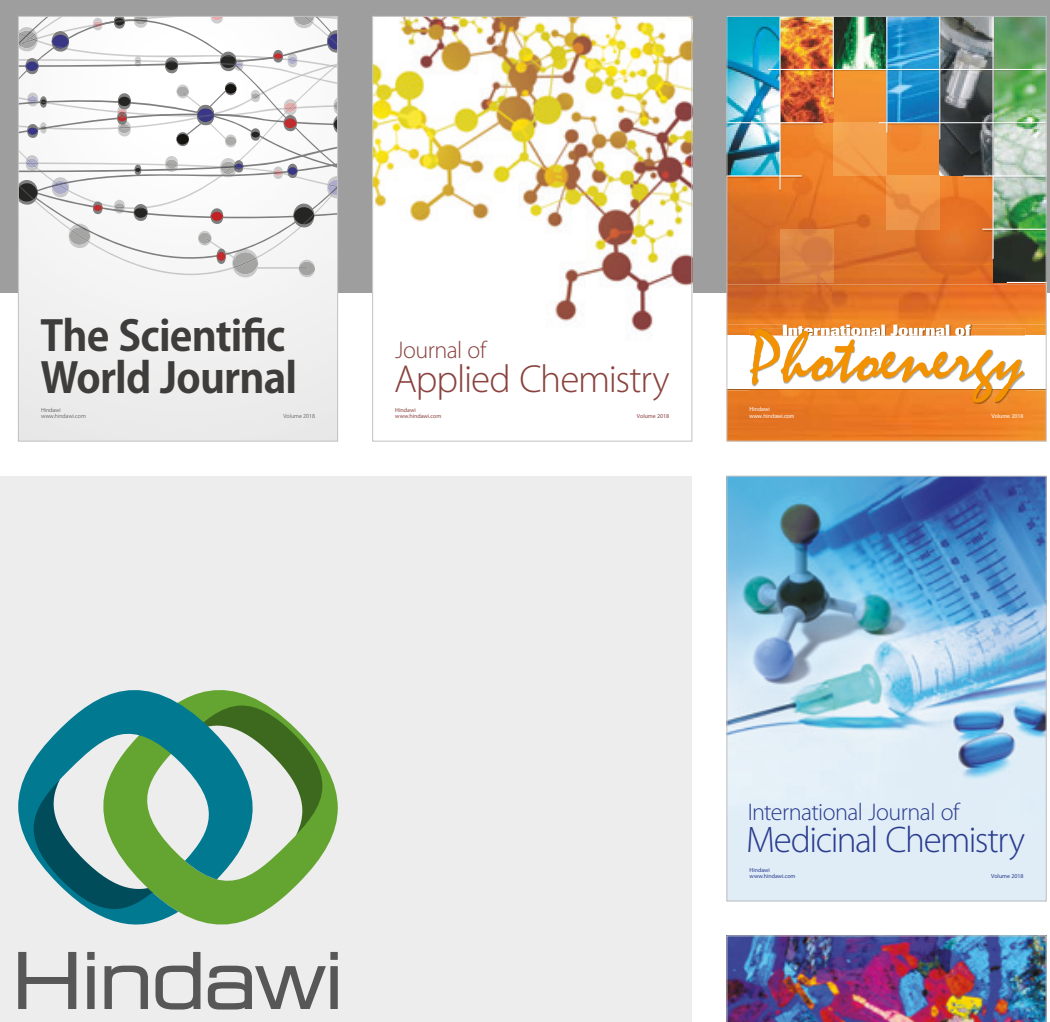

Submit your manuscripts at

www.hindawi.com
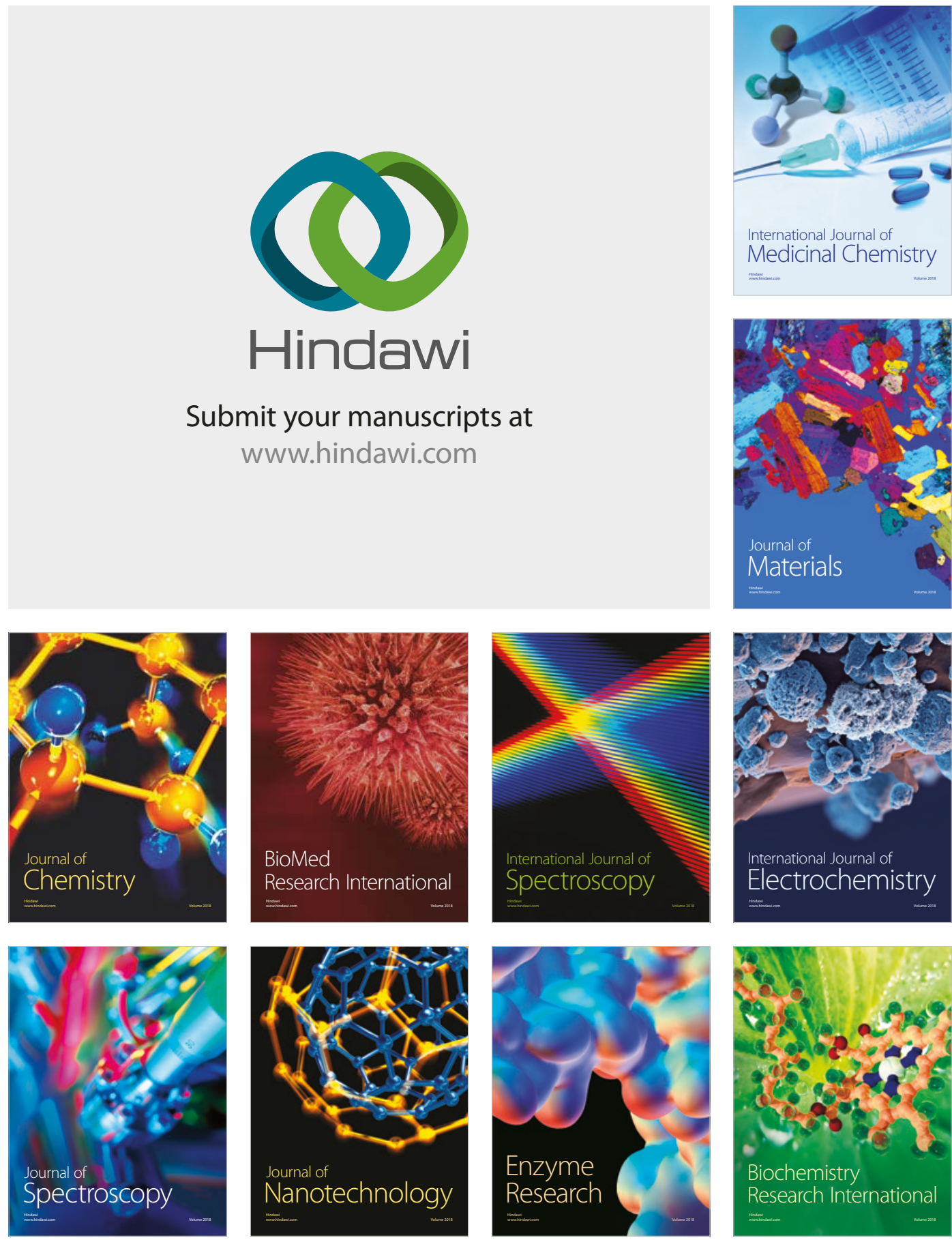
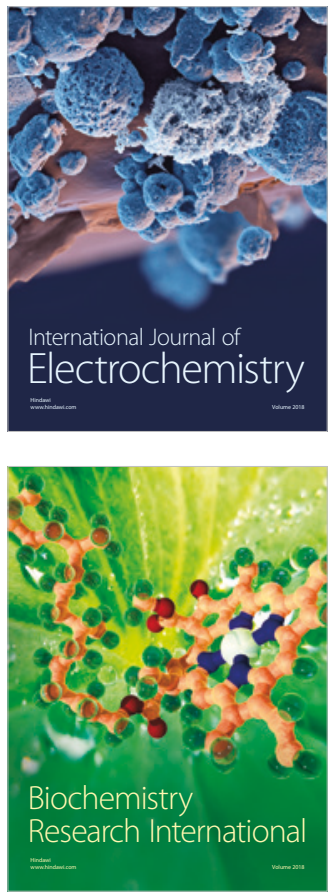